\title{
Alfabetização em países de língua portuguesa
}

\section{Review Literacy in Portuguese-speaking countries}

\section{Reseña La alfabetización en los países de lengua portuguesa}

\author{
Marcela Silva da Luz \\ Universidade Estadual Paulista - SP \\ Andreia Maria Oliveira \\ Universidade Estadual Paulista - SP
}

Oliveira, J.P.; Braga, T.M.S.; Viana, F.L.P.; Santos, AS. (2014). Alfabetização em países de língua portuguesa: pesquisa e intervenção. Curitiba: Editora CRV.

Uma obra de publicação recente e reflexões extremamente pertinentes para a contemporaneidade, o livro "Alfabetização em Países de Língua Portuguesa: Pesquisa e Intervenção" (Editora CRV, Curitiba, Paraná, 246 páginas) foi escrito por pesquisadores brasileiros e portugueses, com um título que revela o abrangente conteúdo da obra: como está o cenário do processo de alfabetização no Brasil e em Portugal, apresentando de que maneira as habilidades metalinguísticas podem favorecer este processo.

O objeto de estudo dos autores neste livro é a análise das habilidades metalingüísticas e seus efeitos no processo de aquisição da linguagem escrita e leitura. O livro é estruturado em catorze capítulos, com temas interconectados com a análise pretendida sobre os mais relevantes pontos das pesquisas em torno do processo de alfabetização.

No primeiro capítulo, Maria Regina Maluf e Renan de Almeida Sagiani apresentam-nos três aspectos importantes para a aprendizagem inicial da linguagem escrita, além de um panorama das pesquisas brasileiras sobre alfabetização e metalinguagem, quantificando as pesquisas realizadas entre os anos 1987 e 2005 de acordo com os temas abordados.

No segundo capítulo, Sylvia Domingos Barrera e Maria José dos Santos analisam o banco de dados da $\mathrm{Bi}-$ blioteca Virtual em Saúde - Psicologia - Brasil no que se refere aos trabalhos científicos brasileiros relacionados às palavras-chave consciência fonológica e habilidade meta- fonológica, aliadas ao descritor intervenção, considerando ainda o período de 2000 a 2012. As autoras localizaram 31 estudos sobre intervenção em consciência fonológica disponíveis para análise e, então, leram na íntegra os trabalhos e os categorizaram, apresentamdo esta organização no decorrer do capítulo.

A intenção das autoras em buscar e analisar as pesquisas de intervenção neste tema se deu em evidenciar o esforço de pesquisadores brasileiros em compreender os benefícios da consciência fonológica para a aquisição da escrita e também em salientar a necessidade da realização de pesquisas de meta-análise.

Bianca Queiroga e Angélica Rosal escrevem o terceiro capítulo do livro, intitulado "Alterações Linguísticas e Metalinguísticas: relações com os processos de alfabetização e letramento", no qual reiteram a importância de cada uma das habilidades metalinguísticas e a sua relação com o processo de aprendizagem da escrita.

No capítulo quatro, as autoras Viviane Barbosa e Sandra Regina Guimarães, conceituam cada uma das habilidades metalinguísticas e em seguida cada uma das habilidades é discutida separadamente.

Ainda nessa direção das habilidades metalinguísticas, a autora Édiva de Souza Martins apresenta um estudo feito com 31 crianças do ensino fundamental que se encontravam em momentos iniciais de aquisição da linguagem 
escrita. Ela analisou a influência das habilidades metassintáticas no reconhecimento de palavras e de compreensão da leitura. Este estudo encontra-se no capítulo sete.

O livro aborda ainda outros importantes subtemas em seus próximos capítulos, tais como: a avaliação da leitura, tratada no capítulo cinco, no qual as pesquisadoras portuguesas Fernanda Leopoldina Parente Viana e Ana Sucena Santos discutem os instrumentos diagnósticos para se realizar uma avaliação eficaz e fidedigna sobre a dificuldade do aluno na leitura.

Nessa perspectiva, outro tema tratado no livro é a intervenção em dislexia. No sexto capítulo, três autores também portugueses (José Sousa, Bruno Dias Martins e Ana Paula Vale) discorrem sobre definição e caracterização da dislexia, além de estruturar componentes e materiais para uma intervenção nesta área. Além disso, os autores fazem um levantamento dos programas de intervenção em dislexia já realizados, ressaltando que não há um programa que possa ser considerado o melhor de todos, mas sim um conjunto de programas que demonstram ter produzido resultados satisfatórios. Após essa análise, os autores apresentam um estudo de caso.

Ainda sobre dislexia, no capítulo oito, Paulo Estêvão Andrade, Olga Valéria Andrade e Simone Aparecida Capellini, apresentam de que maneira a música pode ser utilizada para a identificação de escolares com risco para a dislexia. Além disso, os autores apresentam, através de uma revisão da literatura, a relação entre habilidades musicais e habilidades de leitura-escrita.

Quanto à ortografia, o livro aborda ainda as relações entre percepção de fala e ortografia, pesquisas sobre aquisição da escrita realizadas pelo grupo GPEL/CNPq [Grupo de Pesquisa em Estudos da Língua(gem)] e a avaliação da escrita com ênfase na ortografia. Essa descrição é feita por Ana Cândida Schier e Lourenço Chacon, no capítulo nove.

Ainda sobre este assunto, Jaime Zorzi apresenta uma análise dos erros de grafia em escolares com atraso no processo de alfabetização, no capítulo dez, apresentando ao leitor os diversos tipos de erros que tendem a ocorrer mais com os alunos com dificuldades de aprendizagem, tais como erros por apoio na oralidade, confusão entre as terminações "am" e "ão", entre outros.

E as autoras Simone Capellini e Maria Nobre Sampaio abordam a ortografia com outro enfoque, no capítulo onze. Elas apresentam os resultados de um estudo realizado no Laboratório de Investigação dos Desvios da Aprendizagem (LIDA) da UNESP de Marília, com o propósito de comparar os efeitos de um programa de intervenção para dificuldades ortográficas em escolares com dislexia e dificuldades de aprendizagem. As autoras apresentam o método do estudo, a amostra participante e os resultados comparativos em gráfico, facilitando a compreensão dos dados, e após discutem os resultados de tais comparações, para analisar se o método foi ou não eficaz.
No capítulo treze, as autoras Helena Bolli Mota, Fabieli Thaís Backes, Fernanda Marafiga Wiethan e Roberta Michelon Melo abordam aspectos da intervenção fonológica, bem como as implicações desta no processo de alfabetização. As autoras explicam que a intervenção fonológica, ou seja, a terapia fonoaudiológica com base na fonologia consiste na utilização de modelos estruturados e técnicas, objetivando reorganizar o sistema fonológico das crianças, melhorando a inteligibilidade da fala. E, portanto, essa organização fonológica pode ter implicações diretas na aquisição da leitura e da escrita, já que o sistema de escrita alfabética não representa diretamente o significado da palavra, mas a sequência de seus sons. Portanto, ao longo do texto, as autoras procuram demonstrar que existe uma estreita relação entre as habilidades fonológicas e metafonológicas e o aprendizado da leitura e da escrita.

No penúltimo capítulo do livro, cinco autoras membros do grupo de estudos GEDILPE (Grupo de Estudos Interdisciplinares em Desenvolvimento Infantil, Linguagem e Processos Educativos) apresentam os estudos realizados pelo grupo, que buscam sugerir intervenções com crianças com atraso no processo de desenvolvimento da linguagem escrita, utilizando o tipo textual narrativo. Neste capítulo são focados os trabalhos com o PRONARRAR (programa que visa favorecer o desenvolvimento da leitura e da produção de textos).

No último capítulo do livro é apresentada uma proposta de avaliação da linguagem escrita com foco na habilidade metatextual. Ana Paula Zaboroski e Jáima Pinheiro de Oliveira fazem um estudo das pesquisas de autores brasileiros sobre este tema, situando tal proposta a partir destes estudos, com foco em cinco aspectos: relação da criança com a linguagem escrita, métodos de ensino da linguagem escrita no âmbito escolar, produção escrita da criança, compreensão textual com foco inicial para a produção da criança e avaliações complementares. As autoras sugerem que ao ser solicitado um texto à criança, que este seja solicitado com apoio, que pode ser de diversas maneiras, como apresentação de figuras, brincadeiras, teatro, jogo, entre outras.

A trajetória do livro possibilita que o leitor se aproprie de informações sobre a temática, sem dificuldades, já que são textos de fácil compreensão e organizados de maneira crescente em relação à complexidade do tema, ou seja, o livro apresenta desde conceituação dos termos e pesquisas bibliográficas, a estudos de casos, propostas de intervenção e sugestões de avaliação da leitura e da escrita. Outro aspecto importante é que as pesquisas são recentes, possibilitando um reconhecimento do cenário atual dos estudos em torno do processo de alfabetização. 
Sobre as autoras

Marcela Silva da Luz (marcelaa.sluz@gmail.com)

Discente do curso de Pedagogia na Faculdade de Filosofia e Ciências da Universidade Estadual Paulista - SP.

Andreia Maria Oliveira (andreiapedagogia@gmail.com)

Pedagoga com Habilitação em Deficiência Visual, Faculdade de Filosofia e Ciências, Universidade Estadual Paulista - SP. 